\title{
Dendrochemistry: Ecosystem Services Perspectives for Urban Biomonitoring
}

\author{
Teodoro Semeraro ${ }^{1}$, Andrea Luvisi ${ }^{1}$, Luigi De Bellis ${ }^{1}$, Roberta Aretano ${ }^{2}$, \\ Sandro Sacchelli ${ }^{3}$, Gherardo Chirici ${ }^{3}$, Marco Marchetti ${ }^{4}$ and Claudia Cocozza ${ }^{3 *}$ \\ ${ }^{1}$ Department of Biological and Environmental Sciences and Technologies, University of Salento, Lecce, Italy, ${ }^{2}$ Environmental \\ Consulting, Brindisi, Italy, ${ }^{3}$ Department of Agriculture, Food, Environment and Forestry, University of Florence, Florence, Italy, \\ ${ }^{4}$ Dipartimento di Bioscienze e Territorio, Contrada Fonte Lappone snc, Università Degli Studi del Molise, Pesche, Italy
}

\section{OPEN ACCESS}

Edited by:

loan Cristian loja

University of Bucharest, Romania

Reviewed by:

Jamil Hasan Kazmi,

University of Karachi, Pakistan

Tibor Hartel,

Babeș-Bolyai University, Romania

${ }^{*}$ Correspondence:

Claudia Cocozza claudia.cocozza@unifi.it

Specialty section

This article was submitted to Land Use Dynamics,

a section of the journal

Frontiers in Environmental Science

Received: 04 May 2020

Accepted: 14 August 2020

Published: 15 September 2020

Citation:

Semeraro T, Luvisi A, De Bellis L,

Aretano R, Sacchelli S, Chirici $G$

Marchetti M and Cocozza C (2020) Dendrochemistry: Ecosystem Services

Perspectives for Urban Biomonitoring.

Front. Environ. Sci. 8:558893.

doi: 10.3389/fenvs.2020.558893
The worldwide increase in urban and industrial areas represents a challenge for urban green management, pollutant mitigation and environmental monitoring. We propose an analysis approach for the spatial and spatial-temporal distribution of pollutants in the environment through dendrochemistry techniques, in order to gauge the value of this discipline in urban ecosystem. The proposed analysis models can be useful to evaluate significant changes in space and time related to economic activities and to describe the "impacts" of adopted strategies, as demonstrated in the case study of the opening or closure of factories, and therefore to describe the cause-effect relation connected with human activities. Trees represent a key factor for urban planning, providing a wide variety of ecosystem services including in-depth environmental monitoring, which is one of the main elements to be included in a high quality urban design. The proposed approach aims at suggesting the dendrochemistry as a novel and feasible tool definable as a cost-saving ecosystem service in the urban context.

\section{Keywords: tree rings, trace elements, urban forestry, pollution, ecosystem services}

\section{INTRODUCTION}

The definition of ecosystem services is linked to the capacity to obtain one direct or indirect benefits or services from the ecosystem for human well-being (Costanza et al., 1997; de Groot et al., 2010; Manes et al., 2016). Currently, the definition of ecosystem services is linked to the natural ecosystem characteristics and the technology used to improve human life (Daily, 1997; Marchetti et al., 2019). Therefore, the identification and quantification of the ecosystem services can change with the value that decision-makers give them, considering the different strategies of the biodiversity conservation and planning at different spatial and temporal scales (Semeraro et al., 2019). Positive and negative externalities of the use or loss of many environmental goods and services are still not well-acknowledged (de Groot et al., 2012), for the future assessment of the planning of ecosystem services (Sallustio et al., 2015; Semeraro et al., 2019).

Trees in urban contexts may provide direct benefits such as regulating services, "The services that ecosystems provide by regulating the quality of air and soil or providing flood and disease control, etc" (The Economics of Ecosystems and Biodiversity, 2011), but also yet unassessed benefits for citizenship (Semeraro et al., 2020). Trees absorb pollutants from the environment and accumulate them in tree rings (Cocozza et al., 2016; Perone et al., 2018). The advantage to obtain new service from trees, namely the determination of pollutants in each tree rings might increase the value of urban trees to support the monitoring of 
air quality in the time and in urban environmental strategies and plan development. In this vision, trees are an important tool for the definition of long-term impacts of anthropization (e.g., not well-managed activities of waste management), that in several cases cannot be supported by traditional mobile monitoring stations (e.g., in remote areas).

The last century has showed a significant increase in urban and industrial areas, and future projections are characterized by features such as fast population growth and migrations from rural to urban areas (Marchetti et al., 2014; United Nation, 2014). The consequent environmental and landscape changes require (Marchetti and Pietrobelli, 1996) the monitoring of atmospheric pollution to evaluate the impact of human actions in order to support urban strategies to manage critical environmental issues. Furthermore, environmental and landscape monitoring is one of the main elements to evaluate the quality of urban design and planning (Artiola and Brusseau, 2019). Along these lines, the European Council Directive 85/337/EEC, 2014/52/UE, and the European Directive 2001/42/EC introduced Strategic Environmental Assessment (SEA) and Environmental Impact Assessment (EIA) for the assessment of the potential environmental impacts of projects, plans, and programs (European Parliament Council of the European Union, 2001) on human health. An important aspect introduced by the European directives is to monitor the quality of the environment and landscape and the potential effects or impacts of human strategies and actions on human well-being, ex-ante and ex-post the realization of projects, plans, programs. Therefore, if the monitoring ex-post is always possible also with spatial approaches (Bottalico et al., 2017), the monitoring exante may be limited by a lack of information. In this context, an important role can be played by the analysis of pollutants in tree rings (dendrochemistry) (Baes and McLaughlin, 1984), to obtain environment pollution information (Cocozza et al., 2016; Perone et al., 2018) useful for landscape planning (Sallustio et al., 2019; Alterio et al., 2020), like global environmental change (Fritts and Swetnam, 1989; Amoroso et al., 2017). In this context, urban trees, trees outside forests and in woodlands and forests constitute a fundamental source of historical data and information that may be used to understand how the environment was in the past and how it is evolving along with human activities. In this way, dendrochemistry has the potential to examine the history of contaminant releases by using trees sprawl and present for many years in the landscape independently from urban infrastructure development over time (Burken et al., 2011; Perone et al., 2018). For example, $\mathrm{Cu}, \mathrm{Hg}$, $\mathrm{Pb}$, and $\mathrm{Tl}$ in tree rings were related to the contaminants released from an incinerator in Terni, reflecting the historical variation of environmental pollution in the urban area (Perone et al., 2018).

Following the path tracked by Perone et al. (2018), we want to highlight the potential of the dendrochemistry to extract useful information by giving benefit in environmental and landscapes urban planning for human well-being. So, the purpose of this paper is to define a conceptual model for the spatial and spatialtemporal analysis of pollutants in the environment through dendrochemistry applications for environmental monitoring in urban areas, using the Terni municipality as a case study in order to evaluate the contribution of this discipline in urban planning. In this respect, the concentrations of pollutants in the urban ecosystem can represent important information to relate causes and effects of human actions and strategies for the environmental quality through biomonitoring programs.

\section{CONCEPTUAL MODEL DEFINITION}

The methodology developed in this study used indirect benefits that can be derived by using accumulated pollutants in the urban trees (namely in tree rings), like the result of the regulating services, to develop urban monitoring activities. Mainly, the pollutant levels of tree rings have been used to compare the effects of human activities. Therefore, the methodology is based on the multivariate analysis of the significative differences for pollutant concentrations in tree rings in the time and space realized in relation to human actions or activities in a study case, Terni (Umbria, Italy) (Figure 1A).

\section{Study Case}

The study area is in Terni, one of the most polluted sites in Central Italy (Sgrigna et al., 2016). The city of Terni $\left(42^{\circ} 34^{\prime} \mathrm{N}\right.$; $12^{\circ} 39^{\prime}$ E, elevation $130 \mathrm{~m}$ a.s.l., 112.000 inhabitants) is placed in a valley surrounded by three mountains. Dominant winds are from $\mathrm{N}-\mathrm{NE}$ to $\mathrm{S}$ direction, and the city is characterized by complex environmental human-induced conditions, which compromised the urban environmental quality (www.arpa.umbria.it). The area is characterized by one of the largest (around $150 \mathrm{ha}$ ) stainless steel production site in Europe (Moroni et al., 2013) since 1885, a plant of wastewaters of the steel factory and two storage sites (one for waste and special waste since 1982, and another for dangerous waste since 2006), defined in 2003 as an area of national interest (SNI), "Terni-Papigno" (DM 468/2001 and DMA 08/07/02), for the contamination level. It is also possible to find three incinerators, one of which is not active since 2008, a hospital with a nuclear medicine department, and a waste dump (Mosca, 2008; Perone et al., 2018).

The analysis that we propose in this study is based on the investigation of tree rings carried out by Perone et al. (2018). Sampling survey of tree cores was carried out in proximity of the Terni steel factory, identified as the main pollutant's emitter in the area of Terni. Downy oak (Quercus pubescens Willd.), one of the most common tree species in the surrounding area, was sampled. Four sampling sites were located close to the steel factory, considering the main pollutants emitter in the area: three proximal sites, located around the steel factory at a distance of $1 \mathrm{~km}$ (plot1, plot2, plot3), and one distal site at $5 \mathrm{~km}$ from the plant (plot4) (Figure 1B). Details of trees sampling and pollutant analysis are reported in Perone et al. (2018).

The levels of trace elements in tree rings of trees grown in different location in the study area were analyzed by considering two levels of investigation: (i) spatial (by collecting tree cores in surrounding area to industrial source) and (ii) spatial and temporal (by considering the accumulation of pollutants in tree rings annually formed by sampled trees in years of exposure to industrial source) levels, in order to define the pollutants availability in the environment induced by factories' emissions. 


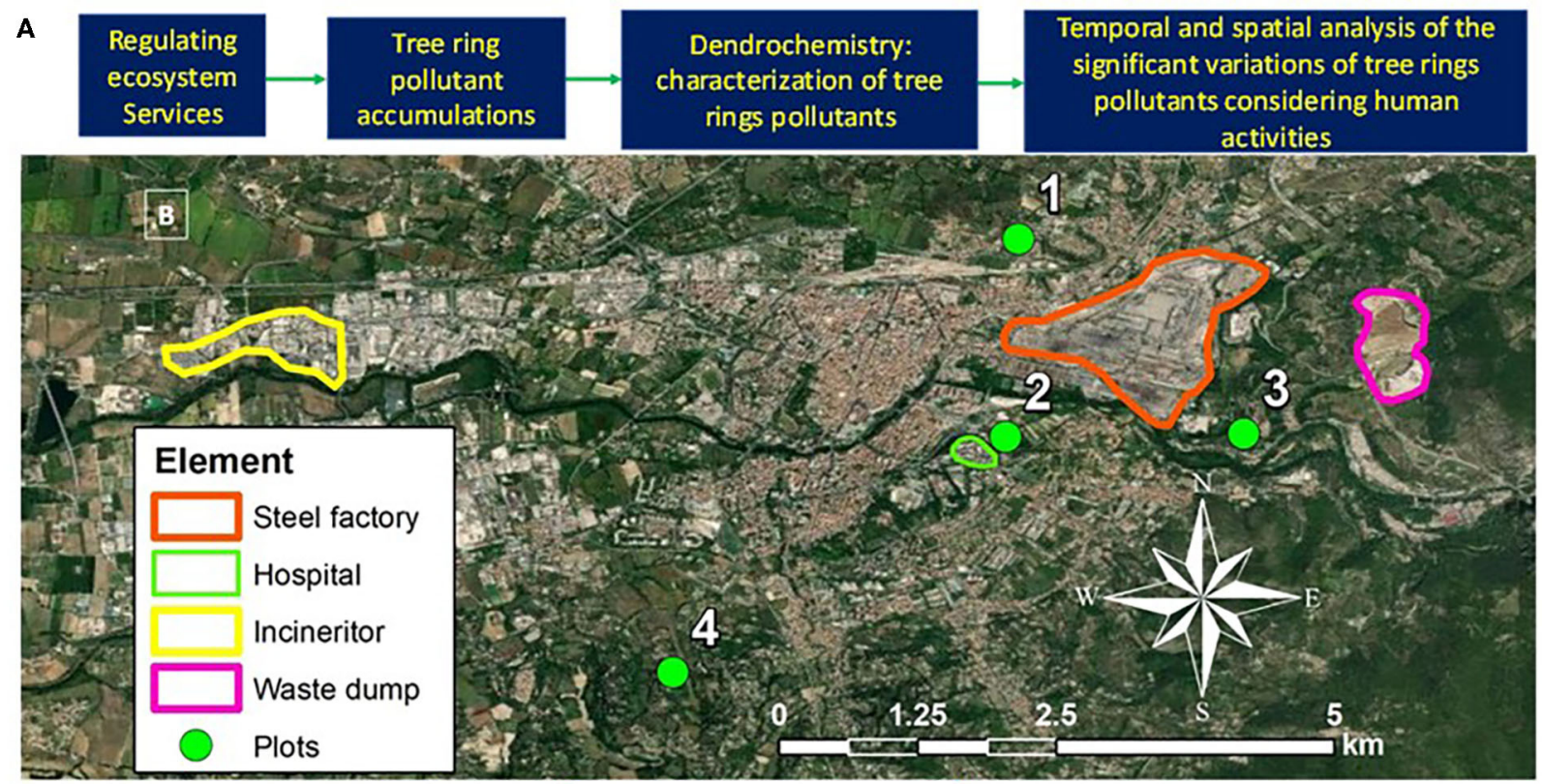

C

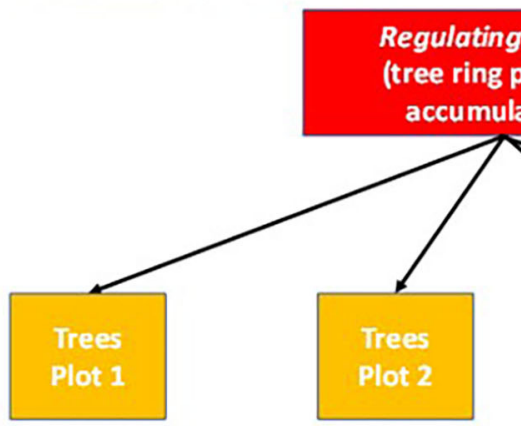

D
E

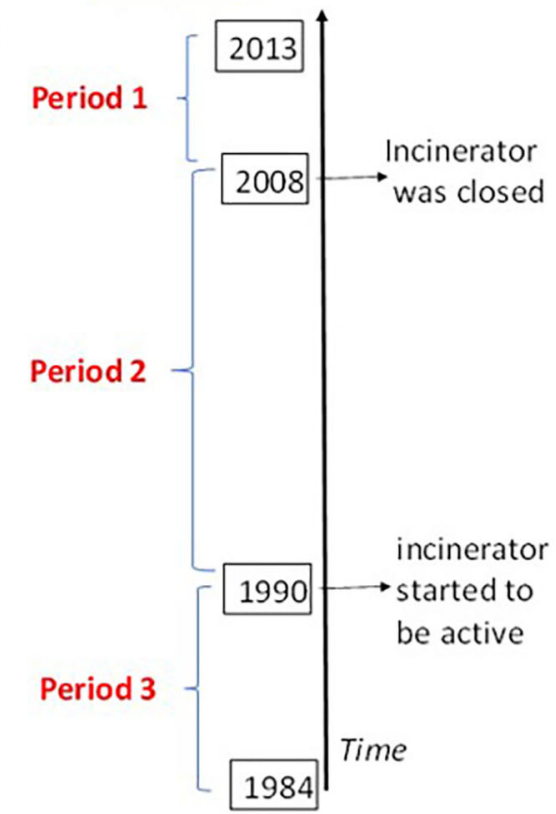

FIGURE 1 | Conceptual model of the definition of pollutants' levels in tree rings in urban area (A); location of sampling plots (B); assessment of the pollutant level in plots 1, 2, 3, 4 (C); assessment of the pollutant's levels in different periods in plot 2 and plot 4 (D); details of industrial history in the study area (E). 
The analysis at different levels was preceded by Levene's test to analyse homogeneity of variance (homoskedasticity). The Levene's test is significant, therefore we reject the Ho hypothesis of equal variances. Therefore, a non-parametric analysis (PERMANOVA) to test the significance of the difference was performed between two or more groups, based on any distance measure (Anderson, 2001). The spatial analysis required a conceptual model that analyse the difference of pollutants in trees located in different plots in reference to the pollutant's emitter, namely the steel factory (plot1, plot2, plot3 and plot4) (Figure 1C). The spatial-temporal analysis combined the effects of the position of the plot 2 and plot 4 in relation to emitters and of the time-steps of the activities change of the incinerator (Figures 1D,E) [period1: no activity of incinerator (2008-2013), period2: activity of biomass power plant incinerator (1990-2008); period3: no activity of incinerator (1984-1990)], intervals of activity detectable in tree rings of trees in the area.

\section{Results}

In the first analysis, the PERMANOVA pairwise comparison indicated that pollutant levels in tree rings were significantly different between plot 4 and plot1, between plot 4 and plot2; while differences of pollutant levels were not found between plot1, plot 2 and plot 3 (Figure 2A).

In the second analysis, the PERMANOVA analysis showed spatial differences of pollutants' levels between plot 2 and plot 4 in period 2 and period 3 , but not a significant difference in period 1 (Figure 2B). Between temporal periods, pollutants' levels were significantly different between period 1 , period 2 and period 3 in plot2 and plot4, whereas the pollutants' levels did not differ between period 2 and period 3 in plot 2 and plot 4 .

The spatial analysis highlighted the effect of distance between trees and the steel factory. By collecting tree cores of trees widely distributed in the environment, the pollutants in tree rings were higher in plots 1,2 , and 3 than in plot 4 , showing that the mapping of pollution risk area highly depended on the distance from the source of pollution. Otherwise, no significant differences emerge that can be traced to the effect of the prevailing wind (from N-NE to S) on the concentration of pollutants in the trees (Figure 3).

The spatial-temporal analysis showed the effect of the distance between emitter and the trees with relevance for temporal exposure to pollutants (Figure 2), highlighting the cause (emission)-effect (storage) relationship of human action to site specificity. The pollutant levels in two sampling plots did not show any differences during the most recent considered period (period 1, when the incinerator was closed), whereas the pollutants' levels were different among plots in the previous years, suggesting a differential effect influenced by the emissions of the incinerator.

However, these differences can also be induced by other factors, such as a reduction in the emission of pollutants from the steel factory and an increase in pollution emissions around plot 4. The average pollution levels in plot 2 tended to decrease from period 3 to period 1 for $\mathrm{Cr}, \mathrm{Pb}, \mathrm{Ti}, \mathrm{U}, \mathrm{V}$, and $\mathrm{W}$, while the average levels of pollutants tended to increase in plot 4 from period 3 to period 1 , except $\mathrm{Cr}$ and $\mathrm{Ti}$, which decreased
(Figure 3). Increasing the number of plots in the space in relation to the human actions that we wanted to analyze, we can have more information to interpret the cause-effect relations of human activities.

To better discriminate the effect of the incinerator, it is necessary to develop specific sampling implementing the number of plots around the incinerators.

\section{DISCUSSION}

The nature of the spatial-based distribution of trees (namely biomonitors) and time-series of industrial history of the area assumes that there are no unique attributes of study area within the measurement set (e.g., spatial) and investigation details across time. Therefore, dendrochemistry can be useful to analyse the spatial and temporal effect of industrial emissions, by analyzing the correlation between causes (human actions and strategies) and effects (variations of the pollution in space and time) of human-induced processes, and provides knowledge and technologies for the biomonitoring of pollutants. In general, the capacity of trees to absorb pollutants is recognized and addressed by physiological processes, aiming to preserve human health with the reduction of exposure risks (Keniger et al., 2013; Sandifer et al., 2015). The potential of pollutants' monitoring through dendrochemistry analysis can describe the medium and long-term effect of human actions, although radial translocation between tree rings remains an aspect to be investigated. Moreover, the physiological process of pollutants' storage in tree rings requires time perhaps not compatible with realtime detection of the effects of emission in the environment. Therefore, dendrochemistry cannot be applied to monitor the exceeding of pollution thresholds in a year (in real time), although it can be applied in a complementary way with a traditional monitoring system or when historical data are not available. The significance of spatial-temporal model, especially in long-term trends, is to simulate the development of pollution over long periods, decades or century, where very old trees are available.

The main elements of the ecosystem, such as trees, are a vector of information in time and space that can be directly used by humans for environmental and landscape planning focused on human well-being. This potential defines the dendrochemistry as a useful tool for the monitoring of a new plan and project, as defined by European directives, by providing an important action to gauge the environmental quality in time and space. Mainly, the use of the information contained in the tree rings can be useful to apply in the descriptive model of environmental variables called DPSIR (Driving forces, Pressures, States, Impacts, Responses) framework that has been adopted by the European Environment Agency (EEA) and used in the Strategic Environmental Assessment (SEA) and Environmental Impact Assessment (EIA) reports (https://www.eea.europa.eu/ help/glossary/eea-glossary/dpsir).

This conceptual model (https://commons.wikimedia.org/ wiki/File:DPSIR.svg) highlights the interactions between the economic, political and social systems with the environmental 


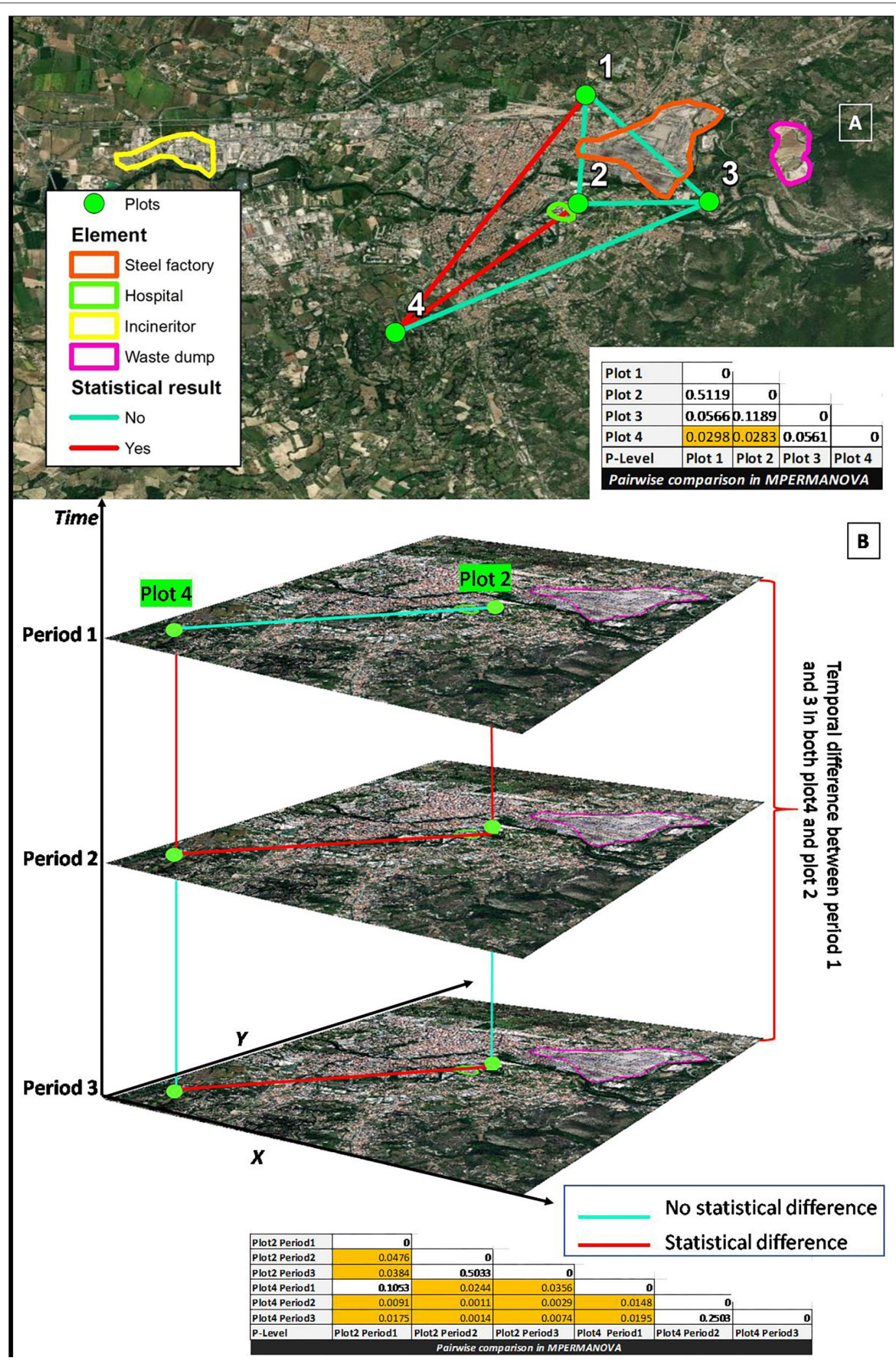

FIGURE 2 | PERMANOVA analysis: P-values of pairwise comparisons of the conceptual model in Figure 1. (A) Representation of the significance differences between plot1, plot2, plot3 and plot4, and (B) representation of the significant differences between period1, period2 and period3 in plot2 and plot4, that are chosen as comparable. The orthophotos used to represent the statistical results in the time and in the space are derived from Bing-Maps. 
$\mathbf{A}$

\begin{tabular}{|c|c|c|c|c|c|c|c|c|c|c|c|c|c|}
\hline Plot & Avarage & Co & $\mathrm{Cr}$ & $\mathrm{Cu}$ & $\mathrm{Hg}$ & Mo & $\mathrm{Ni}$ & $\mathrm{Pb}$ & $\mathrm{TI}$ & $U$ & $\mathrm{~V}$ & $w$ & $\mathrm{Zn}$ \\
\hline \multirow[b]{2}{*}{1} & Average & 0.028 & 0.290 & 0.090 & 0.151 & 0.113 & 0.185 & 0.086 & 0.015 & 0.456 & 0.390 & 0.191 & 0.082 \\
\hline & Std.Dev & 0.021 & 0.137 & 0.083 & 0.152 & 0.086 & 0.189 & 0.088 & 0.017 & 0.447 & 0.263 & 0.195 & 0.107 \\
\hline \multirow[b]{2}{*}{2} & Average & 0.127 & 0.288 & 0.069 & 0.135 & 0.236 & 0.280 & 0.083 & 0.013 & 0.052 & 0.314 & 0.326 & 0.064 \\
\hline & Std.Dev & 0.056 & 0.123 & 0.053 & 0.089 & 0.166 & 0.159 & 0.113 & 0.022 & 0.022 & 0.172 & 0.198 & 0.091 \\
\hline \multirow[b]{2}{*}{3} & Average & 0.016 & 0.201 & 0.210 & 0.219 & 0.117 & 0.139 & 0.122 & 0.021 & 0.013 & 0.189 & 0.217 & 0.035 \\
\hline & Std.Dev & 0.013 & 0.091 & 0.227 & 0.069 & 0.092 & 0.135 & 0.126 & 0.007 & 0.003 & 0.339 & 0.178 & 0.048 \\
\hline \multirow[b]{2}{*}{4} & Average & 0.007 & 0.129 & 0.085 & 0.224 & 0.027 & 0.029 & 0.040 & 0.007 & 0.030 & 0.074 & 0.044 & 0.031 \\
\hline & Std.Dev & 0.011 & 0.041 & 0.035 & 0.075 & 0.026 & 0.051 & 0.027 & 0.004 & 0.038 & 0.032 & 0.021 & 0.032 \\
\hline
\end{tabular}

B

\begin{tabular}{|c|c|c|c|c|c|c|c|c|c|c|c|c|c|c|}
\hline Plot & Period & Parameter & Co & $\mathrm{Cr}$ & $\mathrm{Cu}$ & $\mathrm{Hg}$ & Mo & $\mathrm{Ni}$ & $\mathrm{Pb}$ & $\mathrm{Tl}$ & $\mathbf{U}$ & $\mathrm{V}$ & W & $\mathrm{Zn}$ \\
\hline \multirow{6}{*}{ Plot2 } & \multirow{2}{*}{ Period1 } & Average & 0.196 & 0.157 & 0.251 & 0.267 & 0.250 & 0.333 & 0.050 & 0.012 & 0.034 & 0.089 & 0.072 & 0.155 \\
\hline & & Std.Dev. & 0.128 & 0.082 & 0.229 & 0.172 & 0.049 & 0.117 & 0.026 & 0.010 & 0.020 & 0.034 & 0.025 & 0.067 \\
\hline & \multirow{2}{*}{ Period2 } & Average & 0.154 & 0.204 & 0.078 & 0.170 & 0.118 & 0.173 & 0.093 & 0.016 & 0.077 & 0.237 & 0.209 & 0.039 \\
\hline & & & 0.071 & 0.126 & 0.080 & 0.064 & 0.087 & 0.110 & 0.094 & 0.021 & 0.065 & 0.139 & 0.208 & 0.012 \\
\hline & \multirow{2}{*}{ Period3 } & Average & 0.131 & 0.344 & 0.074 & 0.200 & 0.271 & 0.167 & 0.068 & 0.019 & 0.061 & 0.298 & 0.223 & 0.029 \\
\hline & & Std. Dev. & 0.037 & 0.158 & 0.047 & 0.100 & 0.198 & 0.057 & 0.040 & 0.013 & 0.030 & 0.179 & 0.177 & 0.022 \\
\hline \multirow{6}{*}{ Plot4 } & \multirow{2}{*}{ Period1 } & Average & 0.036 & 0.097 & 0.119 & 0.370 & 0.052 & 0.132 & 0.123 & 0.005 & 0.084 & 0.072 & 0.084 & 0.112 \\
\hline & & Std.Dev. & 0.016 & 0.020 & 0.044 & 0.108 & 0.023 & 0.056 & 0.093 & 0.002 & 0.039 & 0.029 & 0.020 & 0.061 \\
\hline & \multirow{2}{*}{ Period2 } & Average & 0.025 & 0.102 & 0.030 & 0.263 & 0.022 & 0.033 & 0.048 & 0.030 & 0.026 & 0.062 & 0.050 & 0.017 \\
\hline & & Std.Dev. & 0.035 & 0.038 & 0.019 & 0.057 & 0.019 & 0.034 & 0.035 & 0.025 & 0.022 & 0.047 & 0.041 & 0.024 \\
\hline & \multirow{2}{*}{ Period3 } & Average & 0.005 & 0.123 & 0.086 & 0.255 & 0.012 & 0.012 & 0.042 & 0.024 & 0.011 & 0.068 & 0.025 & 0.008 \\
\hline & & Std.Dev. & 0.004 & 0.052 & 0.054 & 0.065 & 0.004 & 0.007 & 0.009 & 0.022 & 0.002 & 0.022 & 0.007 & 0.004 \\
\hline
\end{tabular}

FIGURE 3 | The average value of index level of trace elements (A) in the plots and (B) in the each plot for each period analyzed. The colors from yellow to red refer from the lower to higher average value.

components, according to a cause-condition-effect sequence, in order to provide a multidisciplinary and integrated vision of the various environmental processes. Considering the main human activities that we want to analyse like "Pressures," dendrochemistry can help to describe the "Status" of the environmental matrix and the spatial-temporal differences useful to describe the "Impacts" connected to the human activities stimulating mitigation actions like "Responses." Therefore, the ability to obtain scientific information and fundamental data for environmental and landscape planning both on a local and global scale must be considered as an important ecosystem service.

The proposed analysis can be useful to evaluate significant changes in space and time related to economic activities and to describe the "state" and "impacts" of adopted strategies, such as in the study case the opening or closure of an incinerator and a steel factory, and therefore to describe the effects of the "responses" applied as a consequence of a detected impact. In addition to traditional stations, environmental monitoring can be conducted through the exploitation of trees, which can be found nearly everywhere, do not require any power source and involve a low cost of exercise and analysis. Furthermore, they are plants, thus they provide well-known benefits to urban contests. Luckily, another powerful advantage of dendrochemistry is the unobtrusiveness of the technique, since the dendrochronological method does not compromise tree growth and dynamics. Several simulations incorporate the assumption that improvements in air quality are directly proportional to reductions in environmental emissions (Li et al., 2018). Recently, in Italy, the costs of a mobile monitoring station ( 1 site of monitoring) is around $€ 20.000$, not including equipment management and data analysis. A costeffectiveness analysis of alternative air quality control strategies might consider dendrochemistry, that, with the same budget, produces about 200 measurements, namely the characterization of 200 tree rings (estimating the cost of laser ablation analysis at $€ 100$ per sample and not including equipment management and data analysis). The importance to design the sampling framework is relevant in terms of distribution of pollutants' sources, the availability of trees in the environment and factors influencing the movement of pollutants in the air, in order to define the sampling unit in the specific study area. However, the definition of signals in tree rings in function of the spatial pattern is also related to environmental conditions of the trees' position (e.g., soil, topography, climate) and to vegetation (e.g., growth, physiology) conditions (Dale and Fortin, 2014). For that reason, the sampling unit requires to be defined in relation to the size and distribution of trees in the area, that in the urban context 
is frequently patchy and limited. Therefore, dendrochemistry analysis should be constituted by a minimum of sampling number of unit to select in order to define the effects of pollution in spatial, temporal and spatial-temporal level (e.g., 200 tree rings $=$ minimum 3 plots + minimum 3 trees per each plot to analyse + minimum 3 periods, such as individual year, lustrum or decade to analyse). By adopting this kind of approach, a leastcost strategy to define the level of pollutants in the environment might be obtained designing specific scenarios of biomonitoring for each site. For instance, each urban and industrial area can be differently monitored: (i) 3 plots, 3 trees, 22 individual tree ring; (ii) 5 plots, 5 trees, 8 individual tree ring every 5 (with a retrospective detail 40 age back); (iii) 10 plots, 4 trees, 5 individual tree ring every 5 (with a retrospective detail 25 years back). Although several biomonitoring techniques are available, such as lichens and honeybees (e.g., Olise et al., 2019; Gutiérrez et al., 2020), dendrochemistry can provide retrospective temporal information on pollution absorbance.

Trees represent a pollution data archive, that through dendrochemistry can be made available mainly for ex ante monitoring environmental quality and supporting urban planning processes. For this reason, trees provide useful information for human benefit and can therefore represent direct goods and services to support decision-making processes (Alterio et al., 2020). Consequently, the urban ecosystem can represent an important temporal and spatial information vector that can be classified as ecosystem services. Naturally, this is an indirect benefit because is linked at the capacity of the human to extract environmental ex ante and ex post information and it is obviously not static in the time, but can change following increased knowledge and new potential humans' needs.

However, statistical analysis applied at this type of study cannot represent the truth but helps us to interpret the data with a lower probability of making mistakes. In particular, spatial differences can be influenced by intrinsic characteristics or factors of each point sampling that cannot always be considered in the analysis, such as high buildings, slope, morphology etc., or other sources of pollution unknown to us. Moreover, we believe that the PERMANOVA test is not always the best for this type of study case, because the choice of the statistical test has to realized considering the characteristic of the data. For instance, parametric test bases the significance of the result on the assumption of normality and therefore can be applied only considering specific assumptions, whereas, non-parametric tests are more flexible applications test like PERMANOVA, but $P$-values are obtained using permutations of the objects between the groups, therefore, the result can be less representative of the parametric test (Anderson, 2001). The application of the most appropriate statistical test, mainly between parametric and nonparametric tests, is essential to avoid false-negative results, that is to erroneously conclude that there is no association between the variables of the study case. This would render vain the effort made to design and manage the study in the most appropriate way.

In this context, a transdisciplinary approach that combines different disciplines like physiology, ecology, statistical, urban forestry and planning can improve the capacity of dendrochemistry to produce environmental information from the tree rings useful to human well-being assessment and monitoring. Indeed, the potential of trees to recorder information in space and over time, the capacity of dendrochemistry to extract these information form single trees, the ability of tree physiologists to link the information with the characteristics of the vegetation and the environment's interaction and the capacity of the ecologists to analyse the interaction on this information with the social and economic context of reference and statistic to support right analysis can produce comprehensive results able to support territorial planning activities. Therefore, this approach can produce innovation and increase ecosystem services in urban areas. Its value might grow over time, along with our ability to connect the concentration of pollutants in tree rings with the cause and effect relationships of human actions, considering the wide availability and distribution of trees in the environment. This ability will also be connected with the technological development that will allow us to have tools capable of better refining these analyses.

\section{CONCLUSIONS}

The specific contribution of the paper is to highlight an operational benefits derived by the services of urban tree to evaluate the temporal dynamics of human activities through a multivariate analysis of pollutants in tree rings. Mainly, as discussed for the study case in Terni, the spatial and temporal analysis by studying the same trees over time (e.g., by monitoring the pollutants' storage in the long series of tree rings annually formed by the tree growth) allows to process the environmental effects absolutely necessary in order to reduce environmental risks in an area through urban forest planning. The possibility to link the dendrochemistry at the capacity to obtain ecosystem services for human well-being can increase the value of the tree rings analysis pushing decision-makers and policy to invest in new application projects improving the technologies and knowledge. Moreover, plan the new green space, with this vision in growing cities, can increase the efficiency of the dendrochemistry in environmental monitoring, because the location of specific trees in the cities can be related to the pollution hotspots. In this context, a new vision of the urban green areas plan and design can be applied. Squares, parks or tree-lined rows can be proposed and planned not only for direct services, like human health, but also to monitor human activities and the effect on environmental conditions in time and space at a low cost. The future development of this study will be to connect the spatial and temporal pollutant dispersion with clinical data to link the direct causes of human activities to the effects of specific illnesses. Thus, the urban ecosystem can be useful in areas characterized by the strong industrial activity to assess the social effects of these activities and to apply the right mitigation actions and to estimate social costs.

\section{DATA AVAILABILITY STATEMENT}

The raw data supporting the conclusions of this article will be made available by the authors, without undue reservation. 


\section{AUTHOR CONTRIBUTIONS}

TS and CC: conceptualization, data curation, formal analysis, investigation, methodology, and writing-original draft. TS, CC, AL, LD, RA, SS, GC, and MM: supervision, validation, visualization, and writing-review and editing. All authors contributed to the article and approved the submitted version.

\section{REFERENCES}

Alterio, E., Rizzi, A., Chirici, G., Cocozza, C., and Sitzia, T. (2020). Preserving air pollution forest archives accessible through dendrochemistry. J. Environ. Manage. 264:110462. doi: 10.1016/j.jenvman.2020.110462

Amoroso, M. M., Daniels, L., Baker, P. J., and Camarero, J. J. (Eds.). (2017). Dendroecology. Tree-Ring Analyses Applied to Ecological Studies. Basel, CH: Springer. doi: 10.1007/978-3-319-61669-8_17

Anderson, M. J. (2001). A new method for non-parametric multivariate analysis of variance. Austral Ecol. 26, 32-46. doi: 10.1046/j.1442-9993.2001. 01070.x

Artiola, J. F., and Brusseau, M. L. (2019). The role of environmental monitoring in pollution science. Environ. Poll. Sci. 10, 149-162. doi: 10.1016/B978-0-12-814719-1.00010-0

Baes, C. F., and McLaughlin, S. B. (1984). Trace elements in tree rings: evidences of recent and historical air pollution. Science 224, 494-497. doi: 10.1126/science.224.4648.494

Bottalico, F., Travaglini, D., Chirici, G., Garf,ì, V., Giannetti, F., De Marco, A., et al. (2017). A spatially-explicit method to assess the dry deposition of air pollution by urban forests in the city of Florence, Italy. Urban For. Urban Green. 27, 221-234. doi: 10.1016/j.ufug.2017.08.013

Burken, J., Vroblesky, D. A., Balouet, J. C. (2011). Phytoforensics, dendrochemistry, and phytoscreening: new green tools for delineating contaminants from past and present. Environmental Science Technology 45, 6218-6226. doi: 10.1021/es2005286

Cocozza, C., Ravera, S., Cherubini, P., Lombardi, F., Marchetti, M., and Tognetti, R. (2016). Integrated biomonitoring of airborne pollutants over space and time using tree rings, bark, leaves and epiphytic lichens. Urban For. Urban Green. 17, 177-191. doi: 10.1016/j.ufug.2016.04.008

Costanza, R., d’Arge, R., de Groot, R., Farber, S., Grasso, M., Hannon, B., et al. (1997). The value of the world's ecosystem services and natural capital. Nature 387, 253-260. doi: 10.1038/387253a0

Daily, G. C. (1997). Nature's Services: Societal Dependence on Natural Ecosystems. Washington, DC: Island Press.

Dale, M. R. T., and Fortin, M. J. (2014). Spatial Analysis: A Guide for Ecologists, 2nd Edn. Cambridge: Cambridge University Press. 450. doi: 10.1017/CBO9780511978913

de Groot, R., Bander, L., van der Ploeg, S., Costanza, R., Bernard, F., Braat, L., et al. (2012). Global estimates of the value of ecosystems and their services in monetary units. Ecosyst. Serv. 1, 50-61. doi: 10.1016/j.ecoser.2012.07.005

de Groot, R. S., Alkemade, R., Braat, L., Hein, L., and Willemen, L. (2010). Challenges in integrating the concept of ecosystem services and values in landscape planning, management and decision making. Ecol. Complex. 7, 260-272. doi: 10.1016/j.ecocom.2009.10.006

European Parliament and Council of the European Union (2001). Directive 2001/42/EC of the European Parliament and of the Council of 27 June 2001 on the Assessment of the Effects of Certain Plans and Programmes on the Environment. Official Journal L 197, P. 0030-0037. Avaliable online at: https://eur-lex.europa. eu/ (accessed July 21, 2001).

Fritts, H. C., and Swetnam, T. W. (1989). Dendroecology: a tool for evaluating variations in past and present forest environments. Adv. Ecol. Res. 19, 111-188. doi: 10.1016/S0065-2504(08)60158-0

Gutiérrez, M., Molero, R., Gaju, M., van der Steen, J., Porrini, C., and Ruiz, J. A. (2020). Assessing heavy metal pollution by biomonitoring honeybee nectar in Córdoba (Spain). Environ. Sci. Pollut. Res. 27, 10436-10448. doi: 10.1007/s11356-019-07485-w

\section{ACKNOWLEDGMENTS}

We thank Dr. Paolo Cherubini for precious comments, Prof. Olivier Bachmann, Dr. Marcel Guillong and Dr. Annalisa Perone for the data collection. This work was carried out under the project Establishing Urban FORest based solutions In Changing Cities (EUFORICC), supported by the Ministry of Education, University and Research (MIUR) of Italy (PRIN 20173RRN2S).

Keniger, L. E., Gaston, K. J., Irvine, K. N., and Fuller, R. A. (2013). What are the benefits of interacting with nature? Int. J. Environ. Res. Public Health. 10, 913-935. doi: 10.3390/ijerph10030913

Li, M., Zhang, D., Mulvaney, K. M., Selin, N. E., and Karplus, V. J. (2018). Air quality co-benefits of carbon pricing in China. Nat. Clim. Change 8, 398-403. doi: 10.1038/s41558-018-0139-4

Manes, F., Chirici, G., Munaf,ò, M., Marando, F., Capotorti, G., Blasi, C., et al. (2016). Regulating ecosystem services of forests in ten Italian metropolitan cities: air quality improvement by PM10 and O3 removal. Ecol. Indic. 67, 425-440. doi: 10.1016/j.ecolind.2016. 03.009

Marchetti, M., Lasserre, B., Pazzagli, R., and Sallustio, L. (2014). Rural areas and urbanization: analysis of a change. Scienze del Territorio. 2, 249-258. Available online at: http://www.fupress.net/index.php/SdT/article/view/14333/13324

Marchetti, M., and Pietrobelli, M. (eds.). (1996). "Inquinamento nelle aree urbane: ricerche di base e aspetti applicativi," in Atti del quinto seminario IAED International Association of Environmental Design, Vol 5. (Roma: IAED; CIPLA Perugia) 1-98.

Marchetti, M., Vizzarri, M., and Sallustio, L. (2019). "Towards countryside revival: reducing impacts of urban expansion on land benefits," in Agrourbanism. Tools for Governance and Planning of Agrarian Landscape GeoJournal Library, Vol 124, eds Gottero E. (Cham: Springer), 207-222. doi: 10.1007/978-3-319-95576-6_13

Moroni, B., Ferrero, L., Crocchianti, S., Perrone, M. G., Sangiorgi, G., Bolzacchini, E., et al. (2013). Aerosol dynamics upon Terni basin (Central Italy): results of integrated vertical profile measurements and electron microscopy analyses. Rend. Lincei-Sci. Fis. 24, 319-328. doi: 10.1007/s12210-0130230-8

Mosca, A. (2008). Inceneritore chiuso, 9 indagati. La Procura tira le Somme e Contesta il Reato di disastro ambientale. (Umbria: Corriere dell'Umbria).

Olise, F. S., Ogundele, L. T., Olajire, M. A., Owoade, O. K., Oloyede, F. A., Fawole, O. G., et al. (2019). Biomonitoring of environmental pollution in the vicinity of iron and steel smelters in southwestern Nigeria using transplanted lichens and mosses. Environ. Monit. Assess. 191:691. doi: 10.1007/s10661-0197810-8

Perone, P., Cocozza, C., Cherubini, P., Bachmann, O., Guillong, M., Lasserre, B., et al. (2018). Oak tree-rings record spatial-temporal pollution trends from different sources in Terni (Central Italy). Environ. Poll. 233, 278-289. doi: 10.1016/j.envpol.2017.10.062

Sallustio, L., Perone, A., Vizzarri, M., Corona, P., Fares, S., Cocozza, C., et al. (2019). The green side of the grey: assessing greenspaces in built-up areas of Italy. Urban For. Urban Green. 37, 147-153. doi: 10.1016/j.ufug.2017. 10.018

Sallustio, L., Quatrini, V., Geneletti, D., Corona, P., and Marchetti, M. (2015). Assessing land take by urban development and its impact. Assess. Rev. 54, 80-90. doi: 10.1016/j.eiar.2015.05.006

Sandifer, P. A., and Sutton-Grier, A. E., Ward., B.P. (2015). Exploring connections among nature, biodiversity, ecosystem services, and human health and well-being: opportunities to enhance health and biodiversity conservation. Ecosyst. Serv. 12, 1-15. doi: 10.1016/j.ecoser.2014. 12.007

Semeraro, T., Aretano, R., Barca, A., Pomes, A., Del Giudice, C., Gatto, E., et al. (2020). A conceptual framework to design green infrastructure: ecosystem services as an opportunity for creating shared value in ground photovoltaic systems. Land 9:238. doi: 10.3390/land 9080238 
Semeraro, T., Gatto, E., Buccolieri, R., Vergine, M., Gao, Z., De Bellis, L., et al. (2019). Changes in olive urban forests infected by Xylella fastidiosa: impact on microclimate and social health in urban areas. Int. J. Environ. Res. Public Health 16:2642. doi: 10.3390/ijerph16152642

Sgrigna, G., Baldacchini, C., Esposito, R., Calandrelli, R., Tiwary, A., and Calfapietra, C. (2016). Characterization of leaf-level particulate matter for an industrial city using electron microscopy and X-ray microanalysis. Sci. Total Environ. 549, 91-99. doi: 10.1016/j.scitotenv.2016.01.057

The Economics of Ecosystems and Biodiversity. (2011). TEEB Manual for Cities: Ecosystem Services in Urban Management. Available online at: http://www. teebbweb.org

United Nation. (2014). World Population Prospects: The 2012 Version; Highlights and Advance Table. New York, NY.
Conflict of Interest: RA was employed as an environmental consultant.

The remaining authors declare that the research was conducted in the absence of any commercial or financial relationships that could be construed as a potential conflict of interest.

Copyright (c) 2020 Semeraro, Luvisi, De Bellis, Aretano, Sacchelli, Chirici, Marchetti and Cocozza. This is an open-access article distributed under the terms of the Creative Commons Attribution License (CC BY). The use, distribution or reproduction in other forums is permitted, provided the original author $(s)$ and the copyright owner(s) are credited and that the original publication in this journal is cited, in accordance with accepted academic practice. No use, distribution or reproduction is permitted which does not comply with these terms. 